\title{
An Investigation of the Effect of Modifying and Reusing Impression Copings on Transfer of Implant Analog Position and Angulation
}

\author{
Francisco F Gallardo ${ }^{1}$, Cade A Salmon², Wen Lien ${ }^{3}$, Ryan R Sheridan ${ }^{4}$, Richard C Batzer ${ }^{5}$, Kraig S Vandewalle ${ }^{6}$
}

\begin{abstract}
Aim: The aim of this research was to determine whether sterilization and reutilization of impression copings had an impact on the accuracy of casts made for multiimplant restorations.

Materials and methods: Four master casts embedded with five implant analogs were fabricated. Polyvinyl siloxane (PVS) impressions of the master cast with copings attached to the analogs were made and poured in dental stone. The impression copings were subjected to cleaning and sterilization. These processes were repeated 30 cycles for each of the two groups of five impression copings: one without modification and one with modification that included air abrasion and PVS adhesive. A coordinate measuring machine (CMM) was used to measure relative angles and distances between the reference analog and analogs. The relative angles and distances measured on the stone casts were compared to the master resin cast to obtain positional and angular displacements.

Results: For impression copings that were not modified, a significant difference was detected for both positional and angular displacements. For impression copings that were modified, a significant change was observed only for positional displacement. The maximum discrepancies measured for positional and angular displacements after 30 cycles of reuse were only $81 \mu \mathrm{m}$ and $0.46^{\circ}$, respectively, regardless of the modification. Conclusion: Within the limitations of this study, unmodified impression copings that have undergone 30 cycles of cleaning and sterilization appeared to incur more impression inaccuracy than those impression copings that were modified by airborne-particle abrasion and PVS adhesive. Clinical significance: Impression copings used in this study can likely be recycled up to 30 times without reducing the accuracy of the impression to a level that may be considered clinically significant.

Keywords: Accuracy, Dental implants, Impression copings, Reuse, Sterilization.

The Journal of Contemporary Dental Practice (2020): 10.5005/jp-journals-10024-2789
\end{abstract}

\section{INTRODUCTION}

The high cost of dental implant components has been a driving factor for clinicians to consider reusing certain implant components. ${ }^{1-3}$ However, little is known about the impact of cleaning, impression, and sterilization processes on the properties of implant components. Although some researchers claim that sterilized used impression copings and healing abutments have no visible distortion and are similar to new copings, ${ }^{4}$ other researchers ${ }^{5}$ discourage the reuse of healing abutments due to the residual contaminants present even after cleaning and sterilization of the abutments.

Clinicians often consider reusing metal impression copings because unlike the healing abutments, which stay in the mouth from weeks to months at a time, the impression copings are in the mouth for only a few minutes at a time. Once the cast has been poured, copings may be removed from the impression and sterilized. ${ }^{3}$

Implant-transfer accuracy is an important concern when dealing with an implant-retained prosthesis, ${ }^{6-9}$ especially when reusing implant components. ${ }^{3}$ In a 2013 investigation, Alikhasi et al. ${ }^{3}$ examined the effect of reusing impression copings on the implanttransfer accuracy. The authors concluded that the direct and indirect impression copings could be used and reprocessed without significantly affecting the impression accuracy. Since this study was limited to 10 cycles, the authors added that further research should be accomplished to determine how many times impression copings could be used without affecting impression accuracy. ${ }^{3}$ Vigolo et al. in $2000^{10}$ and $2003^{11}$ concluded that impression accuracy was
${ }^{1}$ USAF Prosthodontics, Advanced Education in General Dentistry Residency, Joint-Base San Antonio-Lackland, Texas, USA

2,4,5 USAF Prosthodontics Residency, Joint-Base San Antonio-Lackland, Texas, USA

${ }^{3}$ USAF Dental Research and Consultation Service, Fort Sam Houston, Texas, USA

${ }^{6}$ USAF Research, Advanced Education in General Dentistry Residency, Joint-Base San Antonio-Lackland, Texas, USA

Corresponding Author: Kraig S Vandewalle, USAF Research, Advanced Education in General Dentistry Residency, Joint-Base San Antonio-Lackland, Texas, USA, Phone: +1 210292 0760, e-mail: kraig.s.vandewalle.civ@mail.mil

How to cite this article: Gallardo FF, Salmon CA, Lien W, et al. An Investigation of the Effect of Modifying and Reusing Impression Copings on Transfer of Implant Analog Position and Angulation. J Contemp Dent Pract 2020;21(3):220-226.

Source of support: 59th Medical Wing, Joint-Base San AntonioLackland, Texas, USA

Conflict of interest: None

improved when impression copings were abraded with airborne particles and polyvinyl siloxane (PVS) adhesive was applied to them. Their findings suggest an improvement in accuracy in a single use but was not tested over multiple usages. ${ }^{10,11}$

The purpose of this research was to determine whether sterilization and reutilization of impression copings, up to 
30 times, has an adverse impact on the accuracy of casts made for multiimplant restorations. A secondary purpose was to determine whether a previously reported method of modifying impression copings (i.e., airborne-particle abrasion with adhesive application) at each reuse would have an impact on the accuracy of the copings over the 30 cycles of reutilization. Finally, this study incorporated implant angulation as a variable to test the accuracy of impressions when copings are repeatedly reused and reprocessed. To the researchers' knowledge, no such studies have been accomplished.

\section{Materials and Methods}

\section{Master Resin Cast Fabrication and Implant Analog Placement}

Four identical resin blocks containing five implant analogs were designed on software (Freeform plus 2014 ed, Geomatic Solutions, Cary, NC, USA, and Solidworks 2014 ed, Dassault Systemes, Waltham, MA, USA). The reference analog (R) was positioned in the middle. Two implant analogs, $A$ and $B$, were placed parallel to $R$. A fourth analog (C) was placed $15^{\circ}$ convergent to R. Lastly, a fifth analog (D) was placed $15^{\circ}$ divergent from $R$. Three index notches were included on the design to confirm proper seating of the custom tray (Fig. 1A). The blocks were fabricated using a stereolithography printer (Viper $\mathrm{si}^{2}$; 3D Systems, Darmstadt, Germany) and resin (Somos Watershed XC11122; DMS Desotech Inc, Elgin, IL, USA). External hex implant analogs (4.1 mm, Zimmer Biomet 3i Implant Innovations, Palm Beach Gardens, FL, USA) were secured in place using clear self-curing resin (Vitacrilic, Fricke International Inc, Streamwood, IL, USA) and were allowed to set for 1 hour. A low-torque-indicating wrench (Zimmer Biomet 3i Implant Innovations, Palm Beach Gardens, FL, USA) was used to confirm that the implant analogs were stable enough to withstand $20 \mathrm{Ncm}$ of torque.

\section{Custom Impression Trays}

Four identical custom trays (thickness $=6 \mathrm{~mm}$ ) were designed and printed using the aforementioned methods. Proper seating of custom trays were confirmed based on matching of the notches on the master resin cast. The custom trays were constructed such that neither the impression copings nor the retaining screws were in contact with the custom tray while open tray impressions were being made.

\section{Modification of Impression Copings}

Open tray impression copings were used (Zimmer Biomet $3 \mathrm{i}, 4.1 \mathrm{~mm}$ $5.0 \mathrm{~mm}$ emergence profile). There were two sets of five impression copings per group. Group I (control) used unmodified impression copings. Group II (experimental group) used modified copings that were abraded with $25 \mu \mathrm{m}$ airborne particles (aluminum oxide; Lincoln Dental Supply, Myerstown, PA, USA) at 30 psi (AccuFlo Micro-Abrasive Blaster; Comco Inc, Burbank, CA, USA) and coated with PVS Tray adhesive (Kerr Corp, Romulus, MI, USA).

\section{Impressions and Cast Fabrication}

The impression copings were attached to their respective implant analogs (Fig. 1B). The retaining screws were hand tightened. To confirm proper seating of impression copings on the implant analogs, a microscope (Leica S4E; Leica Microsystems Inc, Buffalo Grove, IL, USA) with 10× magnification was used to check the presence of any gap between the coping and analog before making impressions. Ten minutes prior to making the impression, a thin layer of PVS adhesive was applied on the custom trays. A PVS impression (Aquasil Monophase; Dentsply Caulk, Milford, DE, USA) was made of the respective reference casts. The impression material was allowed to set for 10 minutes before removing it from the corresponding cast. Implant analogs were attached to each impression coping. The impressions were poured in vacuum mixed (VPM2; Whip Mix, Louisville, KY, USA) type IV dental stone (Silky Rock; Whip Mix, Louisville, KY, USA) and were allowed to set for 1 hour before separating from the impressions. The casts were allowed to set for at least 24 hours prior to the coordinate measuring machine (CMM) measurements.

\section{Cleaning and Sterilization of Impression Copings}

For all groups, the impression copings were removed from the PVS impression, cleaned using a soft bristle toothbrush and detergent soap, then individually bagged (Steriking SS-T1, 3.5X8; Wipak Medical, Nastola, Finland), labeled, and placed in a sterilization tray (Aesculap Inc., Center Valley, PA, USA). Each impression coping was resterilized using a Prevac cycle at $270^{\circ} \mathrm{F}, 30$ psi for 4 minutes of sterilization time and 20 minutes of dry time (Amsco CenturyV$160 \mathrm{H}$, Steris, Mentor, OH, USA). The A, B, C, D, and R positions of the copings were carefully noted. To assure that each impression coping was used on the same position, during cleaning and resterilization, they were placed in clearly labeled individual sterilization bags. All impression copings used in this experiment were placed in one sterilization tray to ensure that they all went through the same sterilization process. An overview of the entire process is depicted in Figures 2 and 3. The entire process was repeated for 30 cycles. All
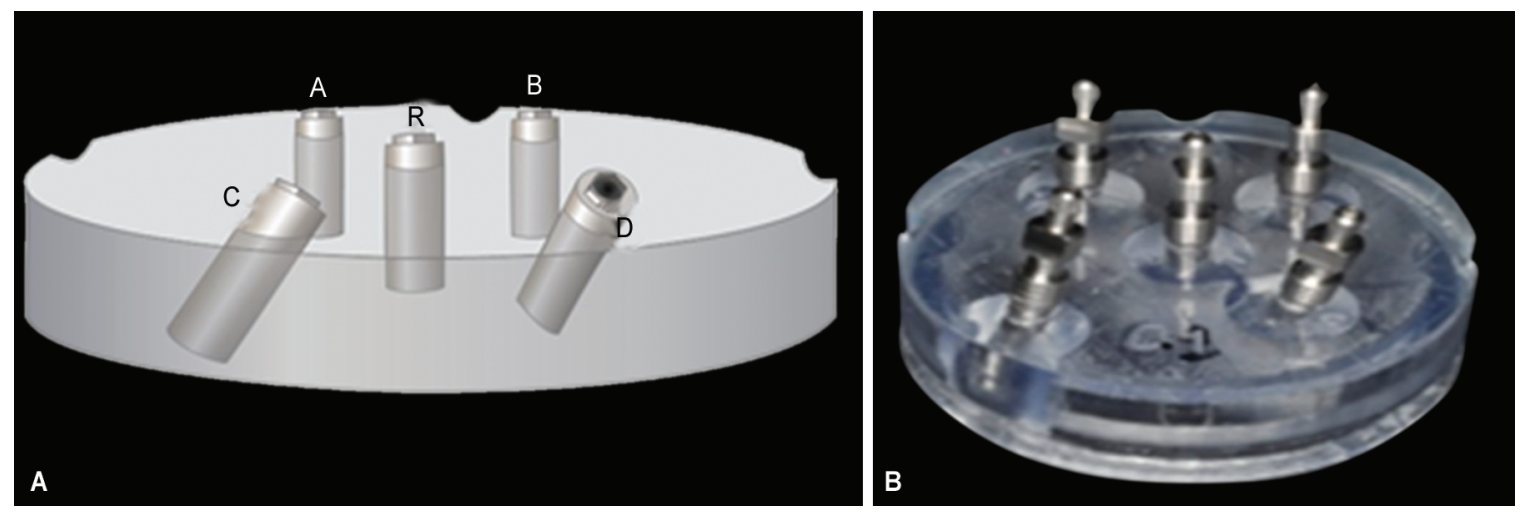

Figs $1 \mathrm{~A}$ and B: (A) Resin cast with two implant analogs (A and B) placed parallel to $R$ (reference analog), one implant analog (C) placed $15^{\circ} \mathrm{convergent}$ to $R$, and one implant analog (D) placed $15^{\circ}$ divergent from $R$; (B) Implant analogs with impression copings in place 


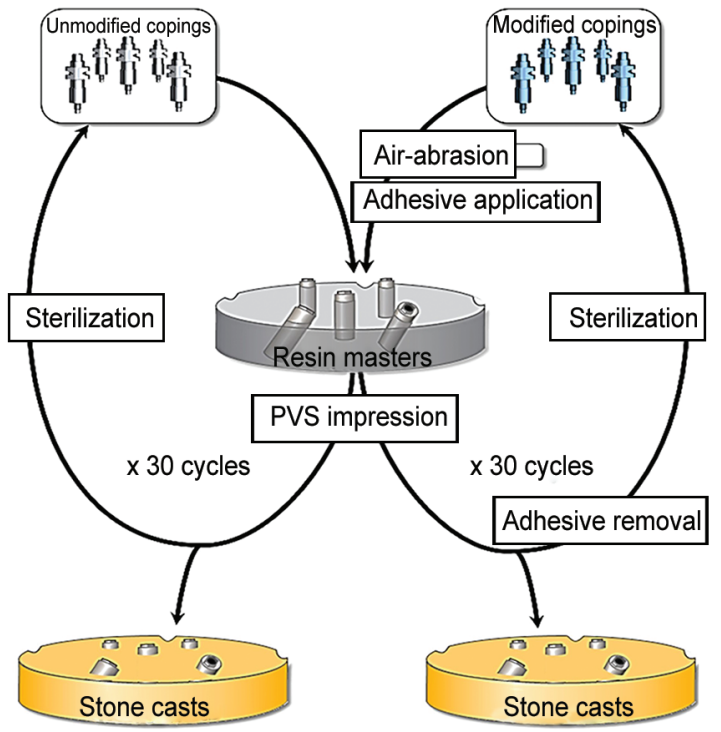

Fig. 2: The processing of impression copings utilized in the study

the experimental procedures were conducted in a dental laboratory in the Air Force Postgraduate Dental School, Lackland Air Force Base, Texas, USA.

\section{Analysis of Implant Transfer Accuracy}

Measurements were done in an Engineering laboratory at Saint Mary's University, San Antonio, Texas, USA. One operator analyzed the transfer accuracy using a CMM (Browne \& Sharpe; Hexagon Metrology, North Kingston, RI, USA) and software (Hexagon Metrology PC-DMIS 2017). The position of the platform center of the external hex of each implant analog was analyzed and recorded using a ruby ball stylus with a $0.5 \mathrm{~mm}$ diameter and $20 \mathrm{~mm}$ tungsten carbide stem (A-5000-1345; Renishaw, Hoffman Estates, IL, USA). Any change to the three-dimensional (3D) position in relation to the reference analog center $(\mathrm{R})$ was determined from this information.
An imaginary line was projected through the axis of each implant analog allowing analysis of their angulation. The angulation of the four implant analogs (A, B, C, and D) was compared to the reference analog $(R)$ on both the stone casts and master resin casts. Then the relative angles and distances measured on the stone casts were compared with the relative angles and distances measured on the master resin cast to obtain discrepancies of positional and angular displacements. This yielded a change in positional value discrepancy $(\Delta P)$ for relative distance and a change in angular value discrepancy $(\Delta A)$ for relative angulation. These discrepancies of displacements were evaluated with a repeated-measures analysis of variance ( $\alpha=0.01$ ) using a statistical software package (SPSS, version 20; IBM, Chicago, IL, USA).

\section{Results}

Within the unmodified group, the $\Delta P$ ranged from $7 \mu \mathrm{m}$ to $81 \mu \mathrm{m}$. The mean $\Delta P$ for this group was 32,41 , and $23 \mu \mathrm{m}$ for the parallel ( $A$ and $B)$, convergent (C), and divergent (D) implant analogs, respectively. The $\Delta A$ for the unmodified group ranged from $0.03^{\circ}$ to $0.46^{\circ}$. The mean $\Delta A$ was $0.2^{\circ}, 0.2^{\circ}$, and $0.1^{\circ}$ for parallel (A and $\left.\mathrm{B}\right)$, convergent $(C)$, and divergent (D) implant analogs, respectively (Fig. 4).

Within the modified group, the $\Delta P$ ranged from $2 \mu \mathrm{m}$ to 59 $\mu \mathrm{m}$. The mean $\Delta P$ were 32,31 , and $28 \mu \mathrm{m}$ for the parallel (A and $B$ ), convergent (C), and divergent (D) implant analogs, respectively. The $\triangle A$ for the modified group ranged from $0.06^{\circ}$ to $0.35^{\circ}$. The mean $\Delta A$ were $0.1^{\circ}, 0.2^{\circ}$, and $0.2^{\circ}$ for the parallel ( $A$ and $\left.B\right)$, convergent $(C)$, and divergent (D) implants, respectively (Fig. 5).

Within the 30 cycles of reutilization and reprocessing of impression copings, there were statistically significant differences on the $\Delta A$ values between the parallel implant analogs ( $A$ and $B$ in relation to the reference implant analog $R$ ) and the $\Delta P$ values between the convergent implant analogs ( $C$ in relation to the reference implant analog $\mathrm{R}$ ) when unmodified impression copings were used. When modified impression copings were used, there were only significant differences in the $\Delta P$ values between the divergent implant analogs ( $D$ in relation to the reference implant analog R; see Table 1). For impression copings that were not modified,

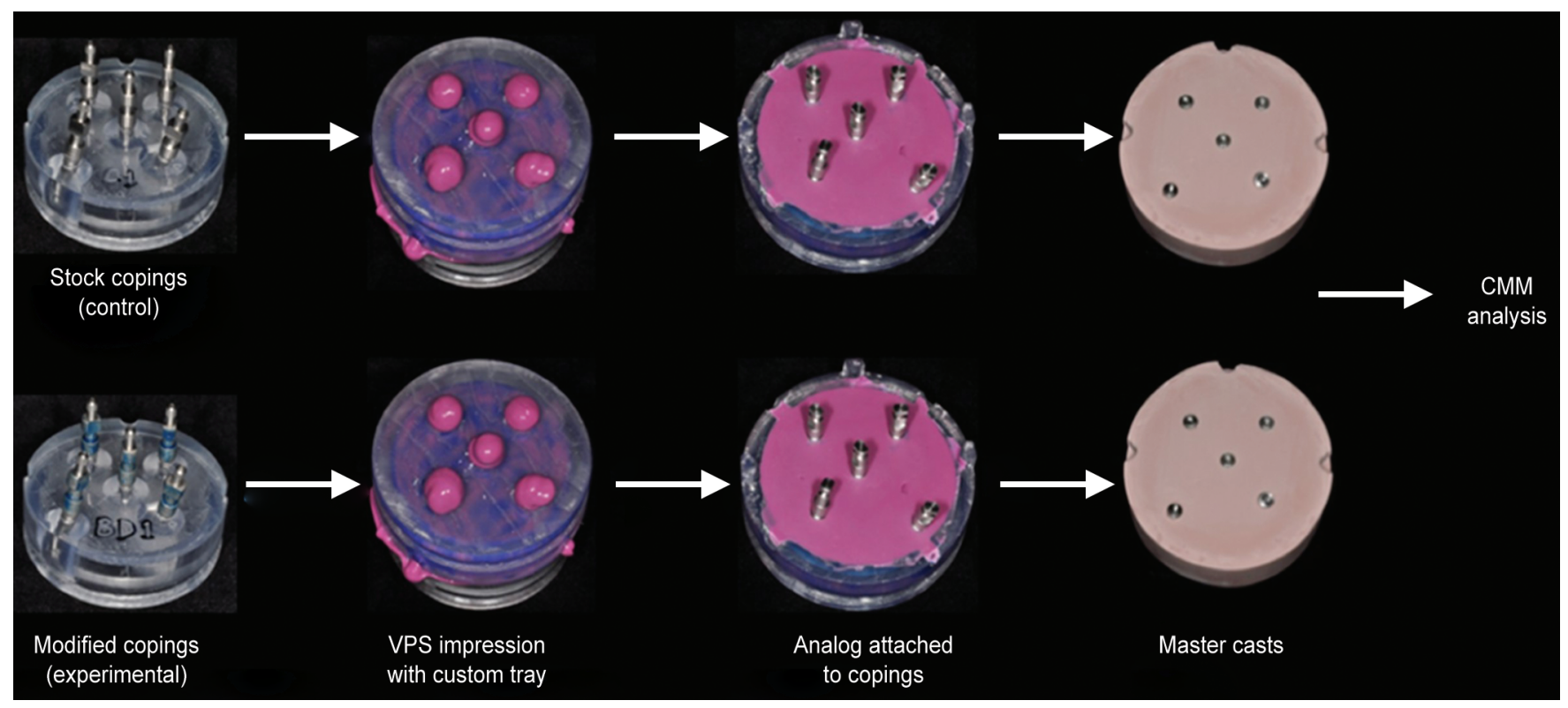

Fig. 3: Workload flow from resin casts with five implant copings through impressions and creation of master casts 

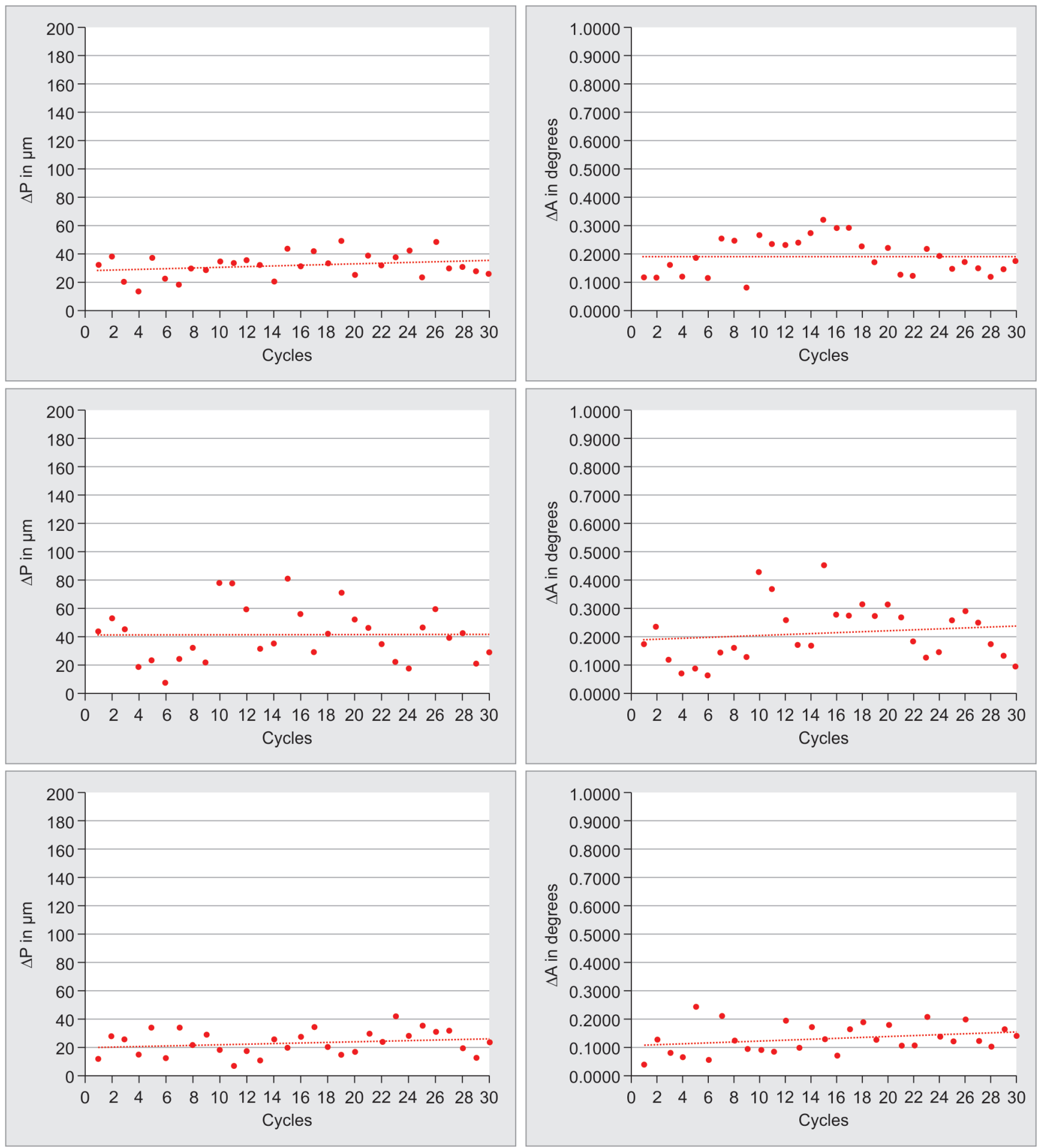

Fig. 4: Graphs of data for unmodified copings. Change in positional value discrepancy $(\Delta P)$ for relative distance and a change in angular value discrepancy $(\Delta A)$ for relative angulation is displayed graphically over 30 cycles for both parallel and divergent implant analogs

two categories of statistically significant differences were detected: parallel angle and convergent distance. For impression copings that were modified, only one category of statistically significant change was observed, which is divergent distance. Throughout the 30 cycles of reuse, the maximum discrepancies measured for positional and angular displacements, regardless of the modification done to the impression copings, were $81 \mu \mathrm{m}$ and $0.46^{\circ}$, respectively.

\section{Discussion}

Restorative success in implant dentistry is dependent upon the ability of a provider and a dental laboratory to create a working cast that accurately replicates the relationship of the dental implants and surrounding structures. In order to accomplish this, implant impression copings are incorporated into the impression process. Many studies compared the accuracy of different impression 

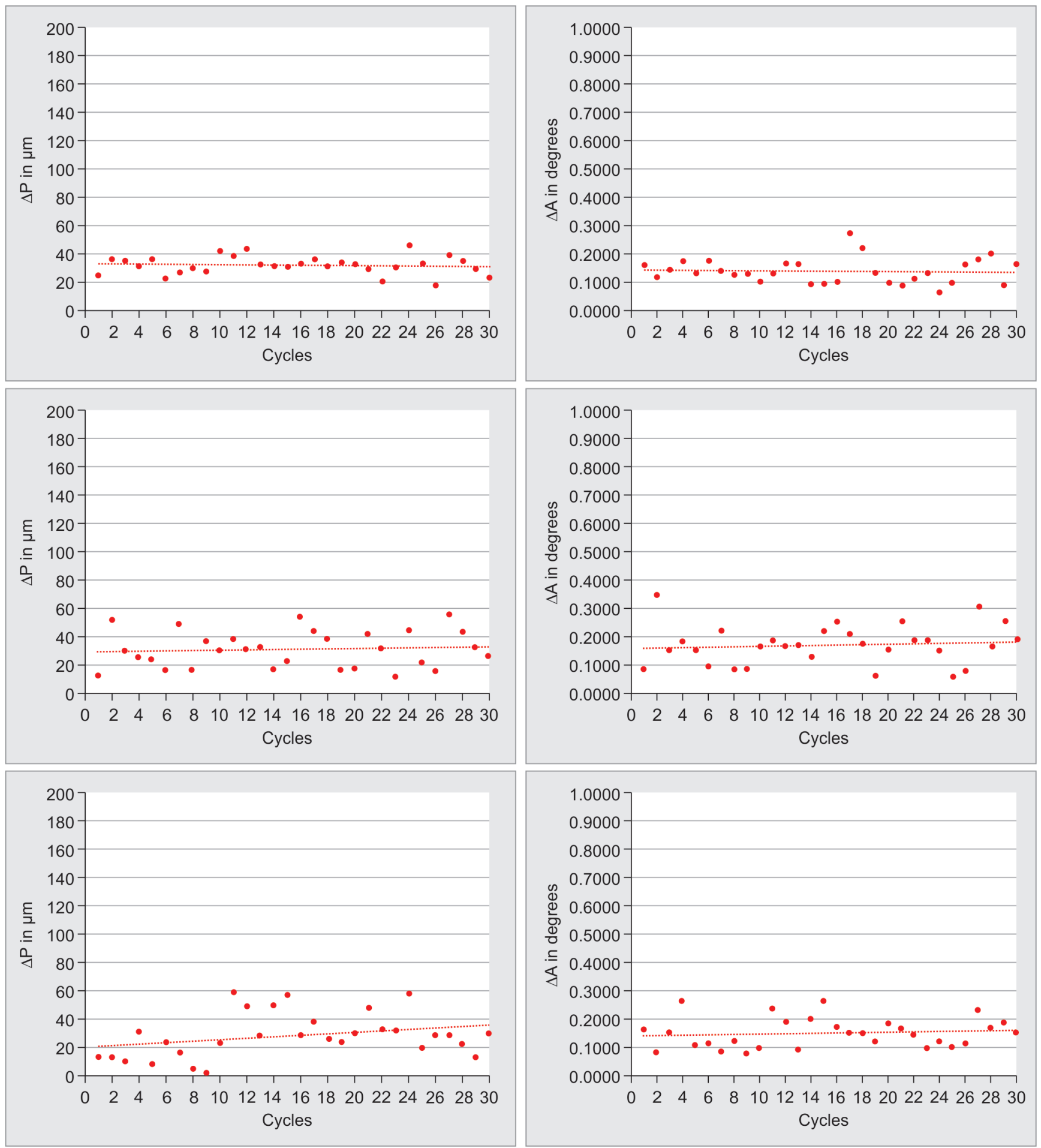

Fig. 5: Graphs of data for modified copings. Change in positional value discrepancy $(\Delta P)$ for relative distance and a change in angular value discrepancy $(\Delta A)$ for relative angulation is displayed graphically over 30 cycles for both parallel and divergent implant analogs

techniques. Lee et al., ${ }^{12}$ in a 2008 systematic review, reported that of the 14 studies $^{13-26}$ considered, there was no consensus as to which of the two techniques, direct or indirect, is more accurate. Various modifications of impression copings have been utilized to investigate possible improvements in impression accuracy. In scenarios with multiple implants, impression copings have been splinted to decrease relative movement during impression making, while readapting copings to analogs. Nevertheless, splinting produces some inherent concerns such as the effects of polymerization shrinkage when polymers are used, and the potential for fracture at the acrylic-coping interface. ${ }^{27}$ Multiple studies have been accomplished to compare the accuracy of splinted and nonsplinted techniques. Although a greater number of studies have indicated that splinting yielded improved accuracy, there is still no consensus as to which technique yields more accurate results. ${ }^{12}$ Economically, it makes sense to reuse impression 
Table 1: The results of repeated-measures analysis of variance $(\alpha=0.01)$ evaluating the change in positional value discrepancy $(\Delta P)$ for relative distance and a change in angular value discrepancy $(\triangle A)$ for relative angulation between the four implant analogs $(A, B, C, D)$ and the reference analog $(R)$ between the stone and master resin casts for both the modified and unmodified copings

\begin{tabular}{|c|c|c|c|}
\hline \multicolumn{2}{|c|}{ Results of repeated-measures of analysis of variance } & \multirow{2}{*}{$\frac{p \text { value }}{0.590}$} & \multirow{2}{*}{$\begin{array}{l}\text { Significant difference } \\
(\alpha=0.01) \\
\text { No }\end{array}$} \\
\hline Unmodified copings & Parallel distance & & \\
\hline & Parallel angle & 0.002 & Yes \\
\hline & Convergent distance & 0.007 & Yes \\
\hline & Convergent angle & 0.041 & No \\
\hline & Divergent distance & 0.599 & No \\
\hline & Divergent angle & 0.409 & No \\
\hline \multirow[t]{6}{*}{ Modified copings } & Parallel distance & 0.988 & No \\
\hline & Parallel angle & 0.087 & No \\
\hline & Convergent distance & 0.750 & No \\
\hline & Convergent angle & 0.900 & No \\
\hline & Divergent distance & $<0.000$ & Yes \\
\hline & Divergent angle & 0.247 & No \\
\hline
\end{tabular}

copings for multiple patients following proper sterilization. Browne et al. found that sterilized used impression copings did not have any visible distortion and were similar to new copings. ${ }^{4}$ Alikhasi et al. also concluded that impression copings could be used and reprocessed up to 10 times without significantly affecting the impression accuracy. ${ }^{3}$

In this study, the relative distance and angulation between parallel, convergent, and divergent implant analogs were measured. Considering only parallel implant analogs, multiple reuses of the unmodified impression copings had a statistically significant effect on the accuracy of analog position reproduction. No significant effects were observed on parallel implant position when modified impression copings were used. This result is in agreement with a previous study by Vigolo et al., ${ }^{11}$ where it was concluded that modification of impression copings significantly improved the accuracy of reproduction of analog position.

Throughout this study, there still was some discrepancy on the accuracy of transfer of abutment position, but this finding was similar to other research by Vigolo et al. ${ }^{11}$ and Alikhasi et al. ${ }^{3}$ The abutment position reproduction discrepancies observed in the 2003 study by Vigolo was around $30 \mu \mathrm{m}$, but the measurements made were limited to two dimensions. ${ }^{11}$ In their study, a machined metal model with six implants and abutments and a corresponding, passively fitting, matching metal template were fabricated. A total of 45 medium-consistency polyether impressions of this model were made with pickup-type square impression copings. Three groups of 15 each were made with different impression techniques: in group I, nonmodified square impression copings were used; in group II, square impression copings were used and joined together with autopolymerizing acrylic resin before the impression procedure; and in group III, square impression copings previously airborne particle-abraded and coated with the manufacturer-recommended impression adhesive were used. Positional accuracy of the abutments was numerically assessed with an optical scanner.

The Alikhasi study showed a discrepancy ranging from $120 \mu \mathrm{m}$ to $420 \mu \mathrm{m}$ in $\Delta P$, and $1.13^{\circ}$ to $3.3^{\circ}$ in $\Delta A .^{3}$ In their study, an acrylic resin cast with five internal connection implants was fabricated. Forty medium-consistency polyether impressions of the cast with direct and indirect techniques were made using four sets (five each) of impression copings (square or conical). Impressions were poured with type IV dental stone. Then the copings were subjected to a cleaning and sterilization process. The process was repeated 10 times with the same copings. Positional accuracy of the implant replica heads in $x-, y^{-}$, and $z$-axes and also angular displacement was assessed using a CMM.

In our research, the highest $\Delta P$ and $\Delta A$ values within the 30 cycles of reusing modified and unmodified impression copings were only $81 \mu \mathrm{m}$ and $0.46^{\circ}$, respectively. Since accurate reproduction is difficult to achieve due to multiple factors such as expansion and shrinkage of dental materials and inherent technique errors, it may come down to the operator's discretion. Reusing impression copings could be considered, however, based on a study by Jempt and Book. ${ }^{28}$ They statistically correlated in vivo measurements of prosthesis misfit and change of marginal bone level in implants placed in the edentulous maxilla. They found that a misfit of 111 $\mu \mathrm{m}$ was clinically acceptable with regard to observed marginal bone loss. ${ }^{28}$

Limitations to this study include a small sample size and the use of only one type of implant system. Measurements using the touch probe were extremely labor intensive. However, 3D laser scanning technology is now available to simplify the measurement process of each specimen. Future studies may also look into the biological implications of reusing impression copings.

\section{ConCLUSION}

Within the limitations of this study, it was determined that unmodified impression copings that have been reused 30 times appeared to incur more impression inaccuracy than those impression copings that were modified by airborne-particle abrasion and PVS adhesive application. The determined statistically significant effect of the reuse process was between parallel and convergent implant analogs for unmodified impression copings and divergent implant analogs for modified impression copings. However, the maximum discrepancies measured for positional and angular displacements after 30 cycles of reuse were only $81 \mu \mathrm{m}$ and $0.46^{\circ}$, respectively, regardless of the modification. 


\section{ACKnOWLedgments}

This research would have not been possible without the kindness of Dr Winston Erevelles and the people of Saint Mary's University Engineering department in San Antonio, Texas, for allowing the use of their CMM.

\section{Disclaimer}

The views expressed in this article are those of the authors and do not reflect the official policy of the US Air Force, the Department of Defense, Uniformed Services University of the Health Sciences, or the US government. The authors do not have any financial interest in the companies whose materials are discussed in this article.

\section{References}

1. Mac Entee MI, Walton JN. The economics of complete dentures and implant-related services: a framework for analysis and preliminary outcomes. J Prosthet Dent 1998;79(1):24-30. DOI: 10.1016/S00223913(98)70189-1.

2. Zinmor CM, Zimmer WM, Williams J, et al. Public awareness and acceptance of dental implants. Int J Oral Maxillofac Implants 1992;7(2):228-232. DOI: 10.1097/00008505-199304000-00017.

3. Alikhasi M, Bassir SH, Naini RB. Effect of multiple use of impression copings on the accuracy of implant transfer. Int J Oral Maxillofac Implants 2013;28(2):408-414. DOI: 10.11607/jomi.2717.

4. Browne V, Flewelling $M$, Wierenga $M$, et al. Sterilization analysis of contaminated healing abutments and impression copings. J Calif Dent Assoc 2012;40(5):419-421.

5. Wadhwani C, Schonnenbaum TR, Audia F, et al. In-vitro study of the contamination remaining on used healing abutments after cleaning and sterilizing in dental practice. Clin Implant Dent Relat Res 2016;18(6):1069-1074. DOI: 10.1111/cid.12385.

6. Del'Acqua MA, Chavez AM, Compagnoni MA, et al. Accuracy of impression techniques for an implant-supported prosthesis. Int J Oral Maxillofac Implants 2010;25(4):715-721.

7. Rashidan N, Alikhasi M, Samadizadeh S, et al. Accuracy of implant impressions with different impression coping types and shapes. Clin Implant Dent Relat Res 2012;14(2):218-225. DOI: 10.1111/j.17088208.2009.00241.x.

8. Chee W, Jivraj S. Impression techniques for implant dentistry. Br Dent J 2006;201(7):429-432. DOI: 10.1038/sj.bdj.4814118.

9. Al Quran FA, Rashdan BA, Abu Zomar AA, et al. Passive fit and accuracy of three dental implant impression techniques. Quintessence Int 2012;43(2):119-125.

10. Vigolo P, Majzoub Z, Cordioloi G. In vitro comparison of master cast accuracy for single-tooth implant replacement. J Prosthet Dent 2000;83(5):562-566. DOI: 10.1016/S0022-3913(00)70015-1.

11. Vigolo P, Majzoub Z, Cordioloi G. Evaluation of the accuracy of three techniques used for multiple implant abutment impressions. J Prosthet Dent 2003;89(2):186-192. DOI: 10.1067/mpr.2003.15.
12. Lee $H$, So JS, Hochstedler JL, et al. The accuracy of implant impressions: a systematic review. J Posthet Dent 2008;100(4):285-291. DOI: 10.1016/S0022-3913(08)60208-5.

13. Carr AB. Comparison of impression techniques for a five implant mandibular model. Int J Oral Maxillofac Implants 1991;6(4):448-455. DOI: 10.1097/00008505-199200130-00017.

14. Barrett MG, de Rijk WG, Burgess JO. The accuracy of six impression techniques for osseointegrated implants. J Prosthodont 1993;2(2): 75-82. DOI: 10.1111/j.1532-849X.1993.tb00387.x.

15. Phillips KM, Nicholls Jl, Ma T, et al. The accuracy of three implant impression techniques: a three-dimensional analysis. Int J Oral Maxillofac Implants 1994;9:533-540.

16. Assuncao WG, Filho HG, ZaniquelliO. Evaluation of transfer impressions for osseointegrated implants at various angulations. Implant Dent 2004;13(4):358-366. DOI: 10.1097/01.id.0000144509.58901.f7.

17. Del'Acqua MA, Arioli-Filho JN, Compagnoni MA, et al. Accuracy of impression and pouring techniques for an implant-supported prosthesis. Int J Oral Maxillofac Implants 2008;23(2):226-236. DOI: 10.1016/S0022-3913(08)60134-1.

18. Humphries RM, Yaman P, Bloem TJ. The accuracy of implant master casts constructed from transfer impression. Int J Oral Maxillofac Implants 1990;5(4):331-336.

19. De La Cruz JE, Funkenbusch PD, Ercoli C, et al. Verification jig for implant-supported prosthesis: a comparison of standard impressions with verification jigs made of different materials. J Prosthet Dent 2002;88(3):329-336. DOI: 10.1067/mpr.2002.128070.

20. Carr AB. Comparison of impression techniques for two-implant 15-degree divergent model. Int J Oral Maxillofac Implants 1992;7(4):468-475. DOI: 10.1097/00008505-199200130-00017.

21. Herbst $\mathrm{D}, \mathrm{Nel} J \mathrm{C}$, Driessen $\mathrm{CH}$, et al. Evaluation of impression accuracy for osseointegrated implant supported superstructures. J Prosthet Dent 2000;83(5):555-561. DOI: 10.1016/S0022-3913(00)70014-X.

22. Naconecy MM, Teixeira ER, Shinkai RS, et al. Evaluation of the accuracy of 3 transfer techniques for implant-supported prostheses with multiple abutments. Int J Oral Maxillofac Implants 2004;19(2): 192-198.

23. Daoudi MF, Setchell DJ, Searson LJ. An evaluation of three implant level impression techniques for single tooth implant. Eur J Prosthodont Restor Dent 2004;12(1):9-14.

24. Conrad HJ, Pesun IJ, DeLong R, et al. Accuracy of two impression techniques with angulated implants. J Prosthet Dent 2007;97(6): 349-356. DOI: 10.1016/S0022-3913(07)60023-7.

25. Cabral LM, Guedes CG. Comparative analysis of four impression techniques for implants. Implant Dent 2007;16(2):187-194. DOI: 10.1097/ID.0b013e3180587b3f.

26. Wenz HJ, Hertrampf K. Accuracy of impression and casts using different implant impression techniques in a multi-implant system with an internal hex connection. Int J Oral Maxillofac Implants 2008;23(1):39-47.

27. Spector MR, Donovan TE, Nicholls Jl. An evaluation of impression techniques for osseointegrated implants. J Prosthet Dent 1990;63(4):444-447. DOI: 10.1016/0022-3913(90)90235-5.

28. Jempt T, Book K. Prosthesis misfit and marginal bone loss in edentulous implant patients. Int J Oral Maxillofac Implants 1996;11(5):620-625. 